\title{
Effects of a community-based intervention package on postnatal care seeking behavior in rural Bangladesh: a cluster-randomized controlled trial
}

\author{
Mohammad Tajul Islam, ${ }^{1}$ Nazrul Islam, ${ }^{2}$ Costas Christophi, ${ }^{3}$ Yukie Yoshimura $^{1}$
}

Keywords: Postnatal care, health seeking behavior, community-based intervention package, clusterrandomized controlled trial, Bangladesh

\begin{abstract}
Background: Community-based Postnatal Care (PNC) initiatives have been found to improve maternal and neonatal health.

Objectives: This paper aims at evaluating the effectiveness of a Community-Based Intervention Package in providing 'limited' PNC services by Community Support Systems (CmSS) and in increasing maternal PNC visits from Skilled Healthcare Providers (SHPs) in rural Bangladesh as well as identifying the predictors of maternal PNC from SHPs.

Methods: A cluster-randomized controlled trial was employed where 6 clusters (each with an average population of about 28,000) of Narsingdi District were randomly assigned to the intervention and the comparison group. Sample sizes for pre- and post-intervention were 675 and 702, respectively, collected in June 2010 and December 2011, respectively, from mothers with a recent live birth. Logistic regression was used in examining the main outcomes and the predictors of maternal PNC from SHPS.
\end{abstract}

Results: The coverage of 'limited' PNC services by the CmSS members to the mothers did not increase significantly $(p=0.25)$, nor did the maternal PNC from SHPS $(p=0.11)$. Both delivery at a Healthcare Facility and delivery by SHPs increased the odds of taking at least one PNC from SHPs 10-fold with 95\% confidence intervals of 4.52-24.04 $(p<0.0001)$ and 4.13$23.84(p<0.0001)$, respectively, adjusting for family income, complicated delivery, and PNC visits by CmSS.

Conclusion: This intervention was found to be effective neither in providing limited PNC services by the CmSS members, nor in increasing maternal PNC from SHPs in our study. Further research with proper monitoring and sufficient number of clusters is recommended.

\footnotetext{
${ }^{1}$ Japan International Cooperation Agency

${ }^{2}$ University of British Columbia Faculty of Medicine

${ }^{3}$ Harvard School of Public Health
}

Please cite this paper as: Islam MT, Islam N, Christophi C, Yoshimura Y. Effects of a community-based intervention package on postnatal care seeking behavior in rural Bangladesh: a cluster-randomized controlled trial. Proc Obstet Gynecol. 2015;5(3): Article 1 [ 20 p.]. Available from: http://ir.uiowa.edu/pog/ Free full text article.

Corresponding author: Nazrul Islam, University of British Columbia Faculty of Medicine, naz@mail.harvard.edu

Financial Disclosure: The project was funded by Japan International Cooperation Agency (JICA). However, JICA did not have any influence on the analysis, interpretation or publication of the data presented in this manuscript.

Copyright: (c) 2015 Islam et al. This is an open-access article distributed under the terms of the Creative Commons Attribution License, which permits unrestricted use, distribution, and reproduction in any medium, provided the original author and source are credited. 


\section{Introduction}

More than two decades after launching the global Safe Motherhood Initiative sponsored by three UN agenciesUNFPA, the World Bank, and WHOmore than 500,000 maternal deaths are attributed to causes related to pregnancy and childbirth, while the number of newborns dying within the first 28 days following birth is as high as 3.6 million. ${ }^{1-3}$ More than 100 countries of the world have eliminated or nearly eliminated maternal mortality as a public health problem. ${ }^{4}$ However, improvement of maternal health up to the Millennium Development Goal target by 2015 still remains a formidable challenge. ${ }^{4}$ Africa and Asia account for $95 \%$ of the world's maternal deaths; half of global maternal death is attributable to sub-Saharan Africa while it is $35 \%$ in South Asia. ${ }^{2,5}$ Bangladesh is one of those six countries that account for half of all maternal deaths each year. ${ }^{4,6}$ Though maternal mortality ratio (MMR) and neonatal mortality rate (NMR) have declined substantially in Bangladesh during the last decades, MMR and NMR are still high-194 per 100,000 and 32 per 1000 live births, respectively. ${ }^{7,8}$

The utilization of skilled attendants at birth is low in Bangladesh covering only one fifth of all deliveries; the situation is even worse in the slums and tribal areas. ${ }^{9}$ An overwhelming $71 \%$ of all deliveries occur at home mostly assisted by Traditional Birth Attendants (TBAs) in Bangladesh. ${ }^{7,10}$ There is a very good network of health service delivery in Bangladesh with health facilities at upazila (sub-district), union (smallest administrative unit in rural Bangladesh) and community levels. ${ }^{11}$ Recently, the
Government of Bangladesh has introduced Community Skilled Birth Attendants (CSBAs) to provide antenatal care (ANC), postnatal care (PNC) and normal delivery services at home for the rural women. ${ }^{12}$ However, utilization of PNC services by mothers is still very low. The proportions of women receiving ante- and post-natal care are $56 \%$ and $27 \%$, respectively. ${ }^{13}$ The burden of maternal complications and deaths is highest in the first few days after delivery, mostly due to hemorrhage, eclampsia and sepsis. ${ }^{8,13}$ Thus, immediate and early postnatal interventions have the potential to improve the maternal health scenario.

Where families have poor access to or do not utilize services from formal health care systems, providing some kind of PNC services by trained community volunteers through home visits has been hypothesized to be an alternative strategy to encourage mothers for skilled PNC services. A comprehensive review of community-based postnatal care initiatives around the globe by Marge Koblinsky showed that it is an effective strategy to improve maternal and newborn health. ${ }^{14}$ Thus integrated community-based postnatal care for mothers is a practical and feasible strategy for reducing deaths and disability in women and newborns. This study tested the effectiveness of a community based intervention by unpaid volunteers to improve skilled PNC seeking behavior of women in a rural area of Bangladesh. 


\section{Methodology}

Setting: The Safe Motherhood Promotion Project (SMPP)

The detailed methodology has been described elsewhere. ${ }^{15,16}$ In brief, the Safe Motherhood Promotion Project (SMPP) was a project of the Bangladesh Ministry of Health and Family Welfare, technically and financially supported by Japan International Cooperation Agency (JICA). The project was implemented in a district (Narsingdi) adjacent to Dhaka, the capital city of Bangladesh from July 2006 to June 2011. The overall aim of SMPP was to improve the maternal and neonatal health situation of the district through establishment of a functional service delivery system for accessing quality obstetric care services by women during pregnancy, childbirth and postpartum period supported by a Community Support System (CmSS).

The project had both public hospital and community-based interventions. Under the hospital interventions, two upazila level hospitals (Raipura and Palash) were strengthened to provide quality comprehensive Emergency Obstetric Care (EmOC) services, while other upazila and district level hospitals were supported to improve quality of EmOC services. The main hospital level activities include supply of necessary equipment, minor renovation of delivery room, operation theatre and female ward, staff (doctors and nurses) training on midwifery, active management of third stage of labor, essential newborn care and neonatal resuscitation, infection prevention practices, and management information system.
On the other hand, major communitybased intervention was the development of a Community Support System (CmSS), at two upazilas (Raipura and Monohardi) of the district. CmSS is a mechanism for establishing a system at the community level through collective efforts of the people which aims at providing support to women during obstetric emergencies. Under the community support system, Community Support Groups (CSGs) were formed to support the poor pregnant women for accessing health services during obstetric complications. Formation of CSG is a self-driven process facilitated by an International Non-government Organization, CARE-Bangladesh, as a partner of JICA. Each CSG covers 150300 households in the community.

The activities of the CSG include household mapping, identification and registration of pregnant women, conducting birth planning sessions with the pregnant women and their family members, educating them on the danger signs of pregnancy and neonates, and providing information on and encouragement for utilization of available maternal and neonatal health care services. The CSGs comprised of 15-22 members (unpaid volunteers), about $50 \%$ of whom were female. The female members are commonly the local TBAs, female member of the Union Parishad (Local Government), nongovernment organization staff, housewives and students. Details about CmSS can be seen elsewhere. ${ }^{17}$

The other community-based intervention was the "Model Union" intervention implemented in nine unions of the district including two in Monohardi 
upazila. Only nine out of 72 unions in the district were selected for the intervention due to resource constraints. Model union interventions comprised of the development of union level plans and a safe delivery team, strengthening of union level health facilities (Health and Family Welfare Centre; or H\&FWC), promoting awareness on birth planning and the danger signs of pregnancy and newborns, and involving the local government in healthcare activities. All the Family Welfare Visitors (FWVs) and CSBAs of the model unions received training on ANC, PNC and a refresher on normal delivery. They also received training on active management of third stage of labor, immediate newborn care and resuscitation, and infection prevention practices. The FWVs (paramedic) are the service providers at H\&FWCs, while the CSBAs are the health (female Health Assistant) and family planning (Family Welfare
Assistant) field staff trained for 18 months to provide ANC, PNC and normal delivery services at home. The model union FWCs received necessary equipment for providing quality ANC, PNC and conducting normal delivery. The delivery room of FWCs was also renovated as required.

\section{Study design and intervention}

This study was a stratified clusterrandomized controlled trial under the common background of SMPP. The study was conducted at six unions (considered as clusters) of Monohardi upazila (sub-district) of Narsingdi district. Monohardi upazila was selected purposively for the study as there was no other intervention (e.g., maternal voucher scheme) in the upazila that might affect the study outcome indicators.

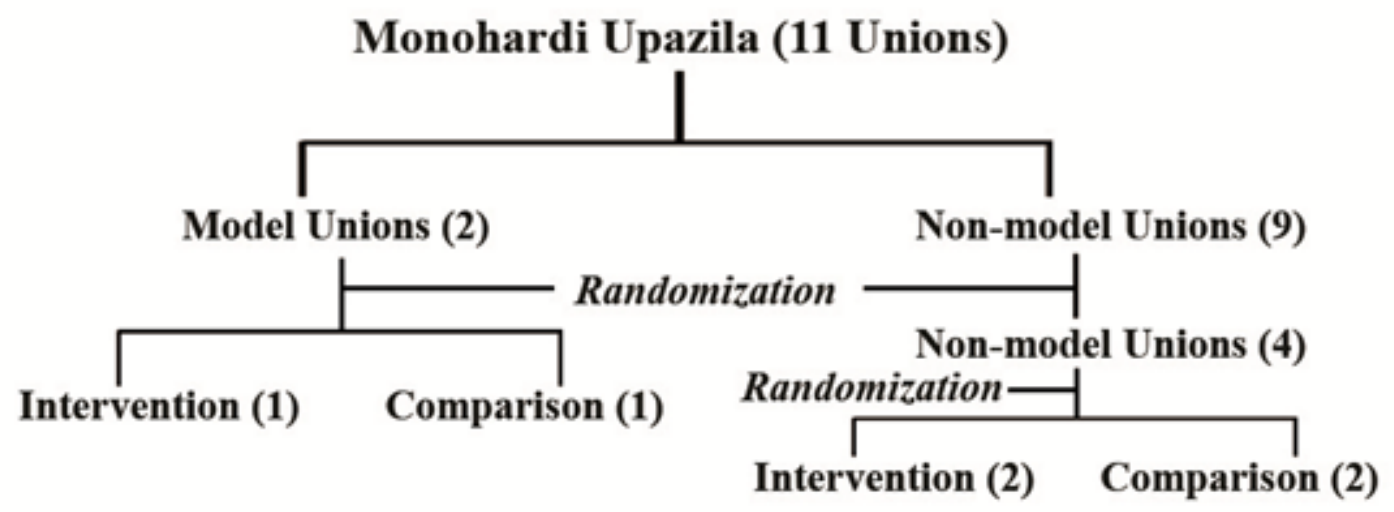

\section{Figure 1: Method of selection of intervention and comparison areas}

Two of the 11 unions at Monohardi upazila had model union interventions. For the selection of intervention areas, the unions were first stratified as model $(n=2)$ and non-model unions $(n=9)$. Out of 9 non-model unions, 6 were selected randomly for random allocation. Randomization was then done 
separately for model and non-model unions to select the unions for intervention $(n=3$; one model and 2 nonmodel unions) and comparison $(n=3$; one model and 2 non-model unions) (Figure 1). The study population was the post-partum women who had a live birth between March 2009 and February 2010 (baseline) and November 2010 and October 2011 (endline). Women who were not the permanent resident (stayed for less than 6 months) of the study area, and had a stillbirth or abortion during the stipulated times were excluded from the study. Basic demographic and other information of the intervention and comparison areas are provided in Table 1.

Table 1: Basic demographic information of study areas at baseline

\begin{tabular}{lcc}
\hline Characteristics & Intervention area & Comparison area \\
\hline Number of unions & 3 & 3 \\
Population & 78,486 & 88,007 \\
Number of community support groups (CSG) & 20 & 15 \\
Population covered by CSGs (\% of total population) & $23,170(29.5 \%)$ & $19,270(21.9 \%)$ \\
Number of population per volunteer & 386 & - \\
Service facilities (no.): & 3 & 3 \\
Family Welfare Centre & $3(1$ residential) & 3 (1 residential) \\
Family Welfare Visitor & 4 & 4 \\
Community Skilled Birth Attendant & & \\
\hline
\end{tabular}

This study was designed to provide limited PNC services (intervention) by the CSG members, who are unpaid volunteers, through three scheduled home visits in line with the recently developed National Neonatal Health Strategy and Guideline for Bangladesh. ${ }^{18}$ The major activities during the visits included counseling of mothers on breast feeding, nutrition, utilization of PNC services by skilled providers and family planning, ensuring essential newborn care, identification of danger signs and referral for complications. The visit schedule and activities are shown in Table 2.

Selection and training of limited PNC providers

In order to provide limited PNC services, 60 members were selected from 20
CSGs (3 from each CSG) of the intervention area through a participatory approach involving the CSG key persons (president and member secretary). The main criteria for selection of CSG members were that they must be an active female member and willing to provide limited PNC services through home visits voluntarily. Preference was given to those who had some formal education. About 30\% of the selected limited PNC providers (hereinafter referred as volunteers) did not have any formal education. Eleven $(18 \%)$ persons were working as "Pushti Kormi" (Nutrition Worker) under the National Nutrition Project, $30 \%$ were TBAs, and the rest were housewives. Only four volunteers dropped out during the project period and were replaced by others. 


\section{Table 2: Schedule and activities of limited PNC visits by the volunteers}

\begin{tabular}{|c|c|}
\hline Visit schedule & Activities \\
\hline \multirow[t]{9}{*}{$\begin{array}{l}\text { 1st visit: within 24-hours of delivery (preferably } \\
\text { during delivery) }\end{array}$} & $\begin{array}{l}\text { Ensure drying and wrapping of baby immediately after } \\
\text { birth by the birth attendant or family members }\end{array}$ \\
\hline & $\begin{array}{l}\text { Ensure immediate breastfeeding (within } 30 \text { minutes of } \\
\text { birth) including colostrums by the birth attendant }\end{array}$ \\
\hline & $\begin{array}{l}\text { Ensure that the baby is not given bath immediately after } \\
\text { delivery }\end{array}$ \\
\hline & $\begin{array}{l}\text { Check baby's breathing and provide tactile stimulation } \\
\text { and refer to health facility/inform health care provider, if } \\
\text { necessary }\end{array}$ \\
\hline & $\begin{array}{l}\text { Check eyes of newborn for infection and refer/inform } \\
\text { the health care provider }\end{array}$ \\
\hline & $\begin{array}{l}\text { Identify, through visual impression, the low birth weight } \\
\text { babies and inform the health care provider }\end{array}$ \\
\hline & $\begin{array}{l}\text { Identify danger signs (especially hemorrhage and } \\
\text { perineal tear, severe headache with blurring vision, } \\
\text { convulsion and fit etc.) of mothers }\end{array}$ \\
\hline & $\begin{array}{l}\text { Identify danger signs of newborn (especially asphyxia, } \\
\text { jaundice and obvious congenital anomaly and refer to } \\
\text { health facility }\end{array}$ \\
\hline & $\begin{array}{l}\text { Notify the Community Skilled Birth Attendant or Family } \\
\text { Welfare Visitor about the delivery }\end{array}$ \\
\hline \multirow[t]{6}{*}{ 2nd visit: 2-3 days of delivery } & Counsel mother on exclusive breast feeding, nutrition \\
\hline & Counsel mother on how to keep baby worm \\
\hline & $\begin{array}{l}\text { Counsel mother to take PNC from skilled persons as per } \\
\text { schedule }\end{array}$ \\
\hline & $\begin{array}{l}\text { Encourage mother for delayed bathing of baby (after } 3 \\
\text { days) }\end{array}$ \\
\hline & $\begin{array}{l}\text { Check danger signs of newborn (eye and skin infection, } \\
\text { jaundice, fever, respiration, diarrhea, feeding difficulty) } \\
\text { and refer to health facility/health care provider, if } \\
\text { necessary }\end{array}$ \\
\hline & $\begin{array}{l}\text { Identify danger signs of mothers (excessive } \\
\text { bleeding/discharge, severe abdominal pain, fever, } \\
\text { convulsion, fit, engorgement of breast) and refer to } \\
\text { health facility, if needed }\end{array}$ \\
\hline \multirow[t]{7}{*}{ 3rd visit: 7-14 days of delivery } & Encourage mothers for exclusive breast feeding \\
\hline & Provide information on nutrition (mother and baby) \\
\hline & Encourage mother to keep the baby worm \\
\hline & $\begin{array}{l}\text { Encourage mothers to take PNC from skilled persons as } \\
\text { per schedule }\end{array}$ \\
\hline & $\begin{array}{l}\text { Provide information to mother on family planning } \\
\text { services }\end{array}$ \\
\hline & $\begin{array}{l}\text { Check the danger signs of newborn and refer to health } \\
\text { facility/health care provider, if necessary }\end{array}$ \\
\hline & $\begin{array}{l}\text { Check the danger signs of mother and refer to health } \\
\text { facility }\end{array}$ \\
\hline
\end{tabular}

To develop the capacity of the volunteers, a 3-day-long training was 
organized in three batches at union level. The objective of the training was to prepare the volunteers with the necessary knowledge and skills to provide limited PNC services to mothers and newborns as per protocol (Table 2). The curriculum for the training was adopted from the National Neonatal Health Strategy and Guideline; training curriculum for the field workers of Maternal, Newborn and Child Health Project supported by UNICEF; and Essential Newborn Care manual developed by Save the Children, USA. The training curriculum included sessions on basic understanding of PNC and its timing; essential newborn care; identification of maternal and newborn danger signs and referral to government health facilities; counseling for exclusive breast feeding and postpartum family planning; and limited PNC visit schedule and things to do. Local government health care providers (FWVs and CSBAs) were formally introduced with the volunteers including their job responsibilities. The volunteers were also provided with the mobile phone numbers of FWVs and CSBAs for birth notification and possible consultation.

The training was skill-based. Pictorial flip charts, baby dolls with cloths, anatomical models (pelvis, breast, and placenta), thermometer, ARI timer etc. were used for demonstration and practical sessions. There were participatory theoretical as well as practical sessions (including role plays) to learn the skills by doing on anatomical models. Upon completion of the training, the volunteers were provided with the necessary logistics, such as two pieces of cloths with a baby doll (to demonstrate drying and wrapping of newborn); thermometer; ARI timer; pictorial flip chart for information, education and communication; maternal and neonatal danger sign cards; bag and umbrella to perform the assigned job during the visits. All the volunteers also received a one-day refresher training after about 3 months practice in the field.

Implementation, monitoring and supervision

The field activities were initiated in November 2010 on completion of the volunteers' training. To implement the project activities, advocacy meetings were conducted at District, Upazila and Union levels with the government staff of health and family planning departments, local government, local elites, and other stakeholders, where design, implementation plan and responsibilities of the stakeholders were clarified.

Household mapping was already available at all the CSGs. All the 60 volunteers were allocated a specific number of households (about 80 per volunteer) to cover. The field monitoring of the volunteers was mainly done by the SMPP $(n=1)$ and CARE-Bangladesh field staff $(n=2)$ through field visits. Monitoring was also done by the CSGs through regular monthly meetings. During the field monitoring visits, the monitors crosschecked with some of the women, who recently gave birth, and about visits by the volunteers. They also observed some of the limited PNC service sessions conducted by the volunteers to assess their knowledge and skills. Based on field observations, 
a one-day refreshers training was organized to reinforce their knowledge and skills. Since a third of the PNC providers were uneducated, it was not possible to introduce any register for recordkeeping and reporting of the field activities. However, all the volunteers provided monthly reports to their respective CSGs verbally. The report included information on the number of pregnant women, deliveries took place, limited PNC provided, and women and neonates referred. All this information was recorded on the CSG register. Reports from CSGs were collected monthly by SMPP and CARE field staff to monitor the activities and performance at central level.

\section{Outcome indicator}

This PNC intervention study primarily tested the hypothesis if limited PNC by the volunteers could increase skilled PNC visits by mothers. The secondary objective of the study was to identify the predictors of taking skilled PNC services by the women. Skilled PNC providers in this study included qualified doctors, nurses, CSBAs, FWVs, Medical Assistants (MAs), and Sub-Assistant Community Medical Officers (SACMOs). Therefore, the main outcome indicator for this study was skilled PNC service utilization by women, who gave birth recently, in the study areas.

\section{$\underline{\text { Data collection }}$}

Two sets of data were collected from both the intervention and comparison areas before and after the intervention. The pre-intervention (baseline) survey was conducted at the intervention $(n=346)$ and comparison unions $(n=329)$ covered by CSGs in June 2010. The target group was all the women who had a live birth between March 2009 and February 2010. All the eligible women living in the study areas were identified through household visits and were interviewed using a pre-tested structured questionnaire. Similar to the baseline survey, an endline (postintervention) survey was conducted in December 2011. The survey used the same questionnaire and methodology as was used in the baseline. The target group for the endline survey was all the women who had a live birth between November 2010 and October 2011 in both the intervention $(n=348)$ and comparison $(n=354)$ areas covered by CSGs.

Hired by the project, 10 data collectors having previous experience in field work, collected data from the study subjects. In addition to SMPP and CARE field staff, two more supervisors were hired for the monitoring and supervision of the field work. All of them were trained for three days on identification of eligible women, questionnaire, and data collection method without disclosing the study hypothesis. Each data collector completed about five questionnaires daily which were checked in the evening by the supervisors for completeness and consistency.

\section{$\underline{\text { Data analysis }}$}

The primary objective of the analysis was to assess the likelihood of taking skilled PNC services if the woman was exposed to intervention controlling for the confounding variables. Data was analyzed by SPSS 16.0 and SAS 9.2 
software in two stages. First, descriptive statistics were computed for the continuous and categorical variables. For comparing the baseline characteristics between the intervention and comparison group, t-test was used for continuous variables and Pearson Chi-square test was used for categorical variables. All the tests were two-tailed with $5 \%$ level of significance.

In the second stage, the effect of intervention on the outcome indicator was evaluated by logistic regression with interaction term (difference-indifference) using both baseline and endline data. Given small number of clusters $(n=6)$, we did not use multilevel (mixed) modeling since estimating intracluster correlation and calculating power becomes unreliable. ${ }^{19}$ Instead, logistic regression considering each subject as the unit of analysis was depicted to be robust. ${ }^{19,20}$ The effectiveness of the intervention on the outcome variable was decided on the adjusted Odds Ratio (OR) and its 95\% confidence interval $(\mathrm{Cl})$ and the significance of the interaction term. All the potential confounders along with the interaction term (interaction between intervention/non-intervention and baseline/endline) were included in the model to check whether the change in outcome variable before and after the intervention was statistically significant taking into account the difference in baseline characteristics. The initial model building followed a stepwise selection process with entry and stay criteria of 0.10 and 0.15 . Variables with a significance level of 0.10 or below were kept in the adjusted model. The final model was set after introducing the intervention and time (baseline/endline) variables with their interaction in the initial model using enter method. For identification of predictors for skilled PNC, only the endline data was used to report the adjusted OR with $95 \% \mathrm{Cl}$.

\section{Ethical consideration}

This study was approved by the Directorate General of Health Services. Informed verbal consent was taken from all the respondents before data collection, and confidentiality and anonymity were maintained throughout.

\section{Results}

Table 3 summarizes the baseline characteristics of the participants in the intervention and comparison groups. The participants in this study were aged between 15 and 45 years across the intervention, with mean age of about 25 . The intervention group had a lower proportion of Muslim women and a higher proportion of women who faced complications during pregnancy, compared to the comparison group.

Table 4 summarizes the changes in the indicator variables in the intervention and the comparison areas after the limited PNC intervention. As evident from the table, more than half $(53 \%)$ of the mothers were visited by CmSS members (PNC providers) in the intervention area during the postpartum period compared to only $31 \%$ in the comparison area. The proportion of mothers who received such visits increased by $7.23 \%$ in the intervention area, while it remained almost unchanged in the comparison area. The change in the proportion of women visited by the CmSS members twice or 
more during the postpartum period was also higher in the intervention area than that in the comparison area (which had a decrease indeed). However, these changes were not statistically significant (the interaction terms were not significant; $p=0.25$ for any limited PNC visit by the CmSS members, and $p=$
0.11 for two or more limited PNC visits by the CmSS members) and were substantially below that what was anticipated, indicating that such an intervention could not make CmSS members visit $100 \%$ of the women.

Table 3: Baseline characteristics of the participants

\begin{tabular}{|lccc|}
\hline Characteristics & $\begin{array}{c}\text { Intervention } \\
(\mathbf{n}=\mathbf{3 4 6})\end{array}$ & $\begin{array}{c}\text { Comparison } \\
(\mathbf{n}=\mathbf{3 2 9})\end{array}$ & p-value \\
\hline Age in years & $24.55 \pm 4.76$ & $24.54 \pm 5.00$ & 0.9828 \\
\hline Muslim & $292(84.39)$ & $308(93.62)$ & 0.0001 \\
\hline Education: Primary or lower & $126(36.42)$ & $141(42.86)$ & 0.0872 \\
\hline Housewife & $331(95.66)$ & $308(93.62)$ & 0.2366 \\
\hline Three or more children & $97(28.03)$ & $97(29.48)$ & 0.6776 \\
\hline Monthly Income $\leq \mathbf{6 , 0 0 0}$ Tk & $195(56.36)$ & $161(48.94)$ & 0.0535 \\
\hline Delivery at home & $258(74.57)$ & $252(76.60)$ & 0.5397 \\
\hline Delivery by Skilled Healthcare Providers & $108(31.21)$ & $82(25.15)$ & 0.0812 \\
\hline Problem faced during delivery & $149(43.06)$ & $84(25.53)$ & $<0.0001$ \\
\hline
\end{tabular}

Data are expressed as Mean $\pm S D$ or Number (Percentage)

Table 4: Change of indicators in intervention and comparison area after the intervention; (\%)

\begin{tabular}{|c|c|c|c|c|c|c|}
\hline & \multicolumn{3}{|c|}{ Intervention area } & \multicolumn{3}{c|}{ Comparison area } \\
\hline & $\begin{array}{c}\text { Baseline } \\
(\mathrm{n}=346)\end{array}$ & $\begin{array}{c}\text { Endline } \\
(\mathrm{n}=348)\end{array}$ & Change & $\begin{array}{l}\text { Baseline } \\
(\mathrm{n}=329)\end{array}$ & $\begin{array}{l}\text { Endline } \\
(\mathrm{n}=354)\end{array}$ & Change \\
\hline \multicolumn{2}{|l|}{} & & & & \\
\hline Post-partum visits by volunteers \\
\hline Any visit & 45.66 & 52.89 & 7.23 & 30.40 & 31.07 & 0.67 \\
\hline $\begin{aligned} \text { Two or more visits } \\
\text { PNC received by skilled providers }\end{aligned}$ & 30.35 & 32.08 & 1.73 & 18.54 & 13.84 & -4.70 \\
\hline Any PNC & 26.59 & 26.72 & 0.13 & 18.24 & 25.14 & 6.90 \\
\hline Three or more PNC & 13.87 & 13.79 & -0.08 & 8.21 & 13.84 & 5.63 \\
\hline
\end{tabular}

In the intervention area, the proportion of women who received at least one PNC from skilled healthcare providers did not increase appreciably while there was an increase by $6.9 \%$ in the comparison area. There was no positive change in taking PNC by skilled persons for 3 or more visits in the intervention area, though it increased by $5.63 \%$ in the comparison area. These changes were also not statistically significant when tested in the logistic regression 
model introducing interaction terms $(p=0.11$ for any PNC visit by the women from the skilled healthcare providers (SHPs), and $p=0.08$ for three or more PNC visits by the women from the SHPs), indicating that the intervention was not effective in increasing maternal PNC from skilled healthcare providers.

Data (post-intervention) were further analyzed to find out the covariates predicting the PNC (by skilled healthcare providers) seeking behavior among the women. Table 5 summarizes the crude odds ratios (OR) showing that all the dichotomous variables except Religion were highly statistically significant for both the outcomes. Age, used as a continuous variable, or as a categorical variable in quartiles (not shown), was not found significant for any of the outcome variables.

\section{Table 5: Crude Odds Ratio for outcome indicators by sociodemographic and other characteristics}

\begin{tabular}{|c|c|c|c|c|c|c|}
\hline \multirow{3}{*}{ Covariates } & \multicolumn{6}{|c|}{ Outcome variables } \\
\hline & \multicolumn{3}{|c|}{$\begin{array}{c}\text { Any PNC visit by skilled } \\
\text { providers }\end{array}$} & \multicolumn{3}{|c|}{$\begin{array}{c}\text { Three or more PNC visits by } \\
\text { skilled providers }\end{array}$} \\
\hline & OR & $95 \%$ CI & p value & OR & $95 \% \mathrm{CI}$ & p-value \\
\hline Age & 0.99 & $0.96,1.03$ & 0.5947 & 1.00 & $0.96,1.05$ & 0.9120 \\
\hline Non-Muslim & 1.24 & $0.74,2.10$ & 0.4125 & 1.04 & $0.53,2.05$ & 0.9071 \\
\hline Education: Secondary or higher & 2.22 & $1.52,3.23$ & $<0.0001$ & 2.69 & $1.60,4.51$ & 0.0002 \\
\hline Non-housewife & 4.14 & $2.07,8.27$ & $<0.0001$ & 4.09 & $1.98,8.42$ & 0.0001 \\
\hline Two or less children & 2.49 & $1.61,3.85$ & $<0.0001$ & 2.79 & $1.52,5.14$ & 0.0010 \\
\hline Monthly income $>6,000 \mathrm{Tk}$ & 1.88 & $1.24,2.84$ & 0.0028 & 2.54 & $1.41,4.60$ & 0.0020 \\
\hline Delivery at healthcare facility & 86.40 & $\begin{array}{l}50.24 \\
148.58\end{array}$ & $<0.0001$ & 100.90 & $\begin{array}{l}39.94 \\
254.91\end{array}$ & $<0.0001$ \\
\hline Delivery by skilled persons & 88.88 & $\begin{array}{l}49.92 \\
158.24\end{array}$ & $<0.0001$ & 189.16 & $\begin{array}{l}45.98 \\
778.17\end{array}$ & $<0.0001$ \\
\hline Had problem during delivery & 12.12 & $\begin{array}{l}8.09 \\
18.14\end{array}$ & $<0.0001$ & 8.79 & $\begin{array}{l}5.51 \\
14.02\end{array}$ & $<0.0001$ \\
\hline \multicolumn{7}{|l|}{$\begin{array}{l}\text { Received limited PNC visit by } \\
\text { volunteer }\end{array}$} \\
\hline Three Visits & 0.74 & $0.43,1.26$ & 0.2628 & 0.27 & $0.11,0.70$ & 0.0062 \\
\hline Two Visits & 0.42 & $0.20,0.87$ & 0.0203 & 0.32 & $0.11,0.91$ & 0.0330 \\
\hline One Visit & 1.08 & $0.70,1.66$ & 0.7285 & 0.82 & $0.47,1.42$ & 0.4701 \\
\hline
\end{tabular}

Cl: Confidence Interval; SHPs: Skilled Healthcare Providers; CmSS: Community Support System

Table 6 summarizes the adjusted analysis of multivariable logistic regression. Religion, despite being significantly different in the intervention and the comparison areas, was not found to be significant predictor for any of the two outcome variables used in the multivariable analysis. Delivery at a healthcare facility (reference category was delivery at home) and delivery by skilled healthcare providers were consistently highly significant predictors 
for both the outcome variables. Delivery at a healthcare facility increased the odds [odds $=$ probability $/(1-$ probability $)]$ of taking any PNC visits by the mothers from SHPs 10-fold (95\% confidence interval (Cl): 4.52, 24.04; $\mathrm{p}<0.001$ ), adjusting for the effects of family income, complicated delivery, delivery by skilled healthcare providers, and 'limited' PNC visits by the CmSS. The odds ratio did not change appreciably when the outcome variable was redefined as taking three or more PNC visits from SHPs, adjusting for the same variables stated above. Delivery by skilled healthcare providers increased the odds of taking at least one PNC visit from SHPs about 10 -fold $(95 \% \mathrm{Cl}: 4.13$, 23.84; $p<0.001$ ), while it increased the odds of taking three or more PNC visits from the SHPs 18-fold with a much wider confidence interval $(95 \% \mathrm{Cl}: 2.98$, $107.81 ; p<0.01$ ), adjusting for the effects of family income, complicated delivery, delivery at a healthcare facility, and 'limited' PNC visits by the CmSS members. Monthly family income of more than 6,000 BDT $(\approx \$ 75$ USD) was a statistically significant predictor for taking three or more PNC from SHPs, increasing the odds by more than twice (95\% Cl: 1.12, 5.06; $p=0.02)$ while it was marginally non-significant $(p=0.07)$ for taking at least one PNC adjusting for other covariates in the model. Facing complications during pregnancy significantly increased the odds by three times (95\% Cl: 1.75, 6.19; $p<0.001)$ of taking at least one PNC from SHPs, while it was marginally non-significant $(p=0.06)$ for taking three or more PNC. Limited PNC visit by CmSS members was not statistically significant for any of the outcome variables across the strata, and there was no specific indication of a significant dose-response relationship for three, two or one visit compared to no visit at all.

\section{Table 6: Multivariable (Adjusted) Analysis}

\begin{tabular}{|c|c|c|c|c|c|c|}
\hline \multirow{3}{*}{ Covariates } & \multicolumn{6}{|c|}{ Outcome variables } \\
\hline & \multicolumn{3}{|c|}{$\begin{array}{c}\text { Any PNC visit by skilled } \\
\text { providers }\end{array}$} & \multicolumn{3}{|c|}{$\begin{array}{c}3 \text { or more PNC visits by skilled } \\
\text { providers }\end{array}$} \\
\hline & OR & $95 \% \mathrm{CI}$ & $\mathrm{p}$ value & OR & $95 \% \mathrm{CI}$ & $\mathrm{p}$ value \\
\hline Monthly Income >6,000 Tk & 1.96 & $0.96,4.02$ & 0.0657 & 2.38 & $1.12,5.06$ & 0.0237 \\
\hline Delivery at healthcare facility & 10.43 & $4.52,24.04$ & $<0.0001$ & 10.40 & $3.11,34.77$ & 0.0001 \\
\hline Delivery by skilled persons & 9.92 & $4.13,23.84$ & $<0.0001$ & 17.92 & $2.98,107.81$ & 0.0016 \\
\hline Problem faced during delivery & 3.29 & $1.75,6.19$ & 0.0002 & 1.79 & $0.98,3.28$ & 0.0600 \\
\hline \multicolumn{7}{|l|}{$\begin{array}{l}\text { Received limited PNC visit by } \\
\text { volunteers }\end{array}$} \\
\hline Three Visits & 1.51 & $0.61,3.74$ & 0.3724 & 0.29 & $0.10,0.85$ & 0.0238 \\
\hline Two Visits & 0.30 & $0.09,0.98$ & 0.0463 & 0.32 & $0.09,1.11$ & 0.0725 \\
\hline One Visit & 1.87 & $0.89,3.93$ & 0.0980 & 1.03 & $0.49,2.16$ & 0.9402 \\
\hline
\end{tabular}

OR: Odds Ratio; Cl: Confidence Interval 


\section{Discussion}

This study was conducted under the common background of SMPP in a typical rural setting of Bangladesh. Our study could not demonstrate positive impact of intervention by trained volunteers on utilization of skilled PNC services by postpartum women. In contrast, several community-based interventions have been found to be effective in reducing neonatal or perinatal mortality. ${ }^{21-28}$ Some studies examined utilization of delivery and maternal health care services including the factors associated with and barriers to utilization of health services in Asia and Africa. ${ }^{29-34}$ Only a few studies looked into healthcare seeking behavior in India, ${ }^{35}$ Nigeria, ${ }^{36}$ and Bangladesh. ${ }^{37-}$ ${ }^{40}$ All these studies analyzed data either from national surveys, ${ }^{39,40}$ or from crosssectional studies. ${ }^{35-38}$ None of these studies, however, examined the effect of well-designed community-based intervention in improving skilled PNC seeking behavior by women.

While local healthcare facilities are in existence, they are not well reached and properly utilized for optimum maternal and neonatal care in Bangladesh. It was expected that community based intervention by volunteers would mobilize the community to utilize the available services for skilled PNC with a view to improving maternal health outcomes and necessary policy change based on evidence. The main strengths of this study were its design and testing of a sustainable and replicable model to improve skilled PNC coverage in a rural setting. Intensive supervision and monitoring of volunteers by the project staff were not employed, deliberately, considering sustainability and replicability of the intervention. However, the project encouraged the CSG members to monitor the activities of the volunteers in the field. But, this strategy did not work as indicated by the low coverage of the target group by the volunteers. There are a number of community-based studies conducted in Bangladesh and elsewhere demonstrating the impact on neonatal mortality reduction but that are not sustainable, at least in the current context in Bangladesh. ${ }^{21,23,24,28}$

This study could not achieve the desired coverage of limited PNC by the volunteers. The volunteers could cover only one third of the births for two or more visits. Lack of intensive field monitoring might be one of the leading reasons for low coverage, which in turn resulted in low skilled PNC uptake by the postpartum women. Low PNC coverage could also be linked with the perceived credibility/faith on and acceptability of the volunteers by the community. The volunteers were not paid for the job. Though they were trained and provided with necessary logistics, but it was perhaps not enough to keep them motivated to provide the services. Further studies are needed to understand the factors, both from the providers' and clients' perspectives, associated with low coverage of limited PNC by the volunteers.

Several factors may have contributed for not realizing any impact on skilled PNC coverage in this study. One of those could be low coverage by the volunteers as discussed earlier. About a third of the volunteers were TBAs in our study. They are still the main rural service providers during childbirth. ${ }^{7}$ Many of them live on the earnings by giving such services. TBAs might be reluctant to encourage mothers to seek skilled PNC 
services, especially when there was no complication due to conflict of interest and credibility. On the other hand, limited PNC by volunteers may have given a sense of security to the postpartum women and their family members that had prevented them from taking skilled PNC services, especially when there was no complication. Other factors for low skilled coverage could be attributed to ineffective counseling to the mothers due to volunteers' inadequate skills.

While social norms and taboos play a vital role in taking PNC services, ${ }^{41-43}$ availability of skilled PNC service providers and their attitude towards clients are crucial for accessing services. In rural Bangladesh, skilled PNC services in the community are available at the Community Clinics (which were not operational during the study period), periodically conducted Satellite Clinics, and H\&FWC at union level. In both the intervention and comparison areas, the designated service providers (FWV and Subassistant Medical Officer) were available at the FWCs along with equal number of SBAs. All of them were advised about the project along with their responsibility.

Monitoring data of SMPP showed that satellite clinics were mostly operational. The responsibility of the volunteers was to provide birth-information to the CSBAs for providing PNC services at home. But, the CSBAs did not respond to such calls positively all the time. It was also reported from the field that the FWV working at one of the intervention clusters was uncooperative and not client-friendly. As most of the data
(68\%) from the intervention areas have come from this union, the negative attitude of the skilled service provider may have affected the study results negatively. However, utilization of health services during pregnancy, delivery and post-partum period are not only related to the availability of health care facilities, they are also largely related to sociocultural norms, lack of women's decision-making power within the family, healthcare spending, distance and lack of availability of suitable transport and perceived low quality of care at the facilities. ${ }^{44-47}$ Further investigation is needed to understand the limiting factors for utilization of skilled PNC services by the postpartum women as this study did not collect such information for further analysis.

The major limitation of the study was the small number of clusters selected for the study. Moreover, the cluster design of the study did not make intervention and comparison groups comparable in terms of all the baseline characteristics which is not quite uncommon in such type of studies. $^{28,48}$ The proportion of women taking at least one PNC by skilled healthcare providers was little less than the national average of $30 \% .{ }^{13}$ Maternal age was not found to be a significant predictor for PNC seeking behavior in this study, while older women were found to seek PNC more than younger women in a study conducted in Bangladesh. ${ }^{30}$ Maternal education was not found to be associated with utilization of skilled PNC services in this study though it was found to be significant in other studies conducted in Bangladesh. ${ }^{49,50}$ Higher monthly family income was found to be a positive predictor for three or more PNC visits in 
this study which is compatible with the findings from another study. ${ }^{30}$ This finding is also supported by the data from a national survey. ${ }^{13}$

\section{Conclusion and recommendations}

It may be concluded from this study that, volunteer-dependent community-based limited PNC intervention might not be effective in improving utilization of skilled PNC services in rural Bangladesh. Important predictors for PNC by skilled providers identified in this study included delivery at health facility, delivery by skilled providers, higher monthly family income, and having complications during delivery. We provide the following recommendations, based on the lessons learnt, for evaluating such kinds of intervention studies in the future.

Further studies to understand the social context and other factors related to low uptake of skilled PNC by the postpartum women are recommended.

The capacity building of volunteers is very important for such kinds of intervention trials. In our study $30 \%$ of the volunteers were uneducated and it was not easy to train them to provide the desired services. It would perhaps be better to select volunteers with some formal education. In such case, it would have been easier to train them up and introduce register for recordkeeping and reporting for better monitoring of field activities.

Regular follow-up and field monitoring are imperative especially to ensure services both by the volunteers and skilled service providers, which the project did not do deliberately. Other sustainable mechanisms need to be identified for effective field monitoring. One of the ways could be to organize regular formal meetings jointly with the volunteers, government service providers and their supervisors to monitor the activities and discuss field problems. This could also be an opportunity to improve the volunteers' skills through these meetings. Such meetings could also be helpful to strengthen the linkage between volunteers and skilled service providers.

About a third of the PNC providers were TBAs. They had their own personal interest in maternal care creating a conflicting situation. As a result, they might be less likely to refer mothers for skilled PNC services available at the union, especially when there was no complication. Decision on involvement of TBAs in such kind of interventions should be considered cautiously.

The authors acknowledge the immense contribution of Professors Julie Buring, James Ware, John Evans, Drs Andrie Panayiotou, Konstantinos Makris, Panayiotis Yiallouros for their review, suggestions and guidelines at different stages of preparing this manuscript. This study was financially and technically supported by JICA, Bangladesh under Technical Cooperation Project category.

\section{References}

1. Starrs AM. Safe motherhood initiative: 20 years and counting. Lancet. 2006 Sep 30;368(9542):1130-2. http://dx.doi.org/10.1016/S01406736(06)69385-9 PubMed PMID: 17011924 
2. UNICEF. Maternal and Newborn Health, The State of the World's Children 2009. The United Nations Children's Fund (UNICEF), 2009. http://www.unicef.org/cotedivoire/SOWC 2009 .pdf

3. Lawn JE, Kerber K, Enweronu-Laryea C, Cousens S. 3.6 million neonatal deaths--what is progressing and what is not? Semin Perinatol. 2010 Dec;34(6):371-86.

http://dx.doi.org/10.1053/i.semperi.2010. 09.011 PubMed PMID: 21094412.

4. UNFPA. The Maternal Health Thematic Fund Annual Report 2010. United Nations Population Fund (UNFPA), 2011.

http://www.unfpa.org/publications/mater nal-health-thematic-fund-annual-report2011

5. Carlo WA, Goudar SS, Jehan I, Chomba E, Tshefu A, Garces A, Parida S, Althabe F, McClure EM, Derman RJ, Goldenberg RL, Bose C, Krebs NF, Panigrahi $\mathrm{P}$, Buekens $\mathrm{P}$, Chakraborty $\mathrm{H}$, Hartwell TD, Wright LL; First Breath Study Group. Newborn-care training and perinatal mortality in developing countries. N Engl J Med. 2010 Feb 18;362(7):614-23.

http://dx.doi:10.1056/NEJMsa0806033

PubMed PMID: 20164485

6. Hogan $M C$, Foreman $\mathrm{KJ}$, Naghavi $\mathrm{M}$, Ahn SY, Wang M, Makela SM, Lopez $A D$, Lozano R, Murray CJ. Maternal mortality for 181 countries, 1980-2008: a systematic analysis of progress towards Millennium Development Goal 5. Lancet. 2010 May 8;375(9726):1609-23. http://dx.doi.org/10.1016/S01406736(10)60518-1 Epub 2010 Apr 9. PubMed PMID: 20382417.
7. BDHS. Bangladesh Demographic and Health Survey 2011: Preliminary Report. National Institute of Population Research and Training, Dhaka, Bangladesh; Mitra and Associates, Dhaka, Bangladesh; MEASURE DHS, ICF International, Calverton, Maryland, USA, 2012. http://dhsprogram.com/publications/publi cation-fr265-dhs-final-reports.cfm

8. NIPORT, icddr b, MEASURE Evaluation. Bangladesh National Maternal Mortality and Health Care Survey 2010. Dhaka, Bangladesh: National Institute of Population Research and Training (NIPORT), MEASURE Evaluation, and icddr,b, 2012.

http://www.cpc.unc.edu/measure/publica tions/tr-12-87

9. BBS UNICEF. Key Findings: Multiple Indicators Clusters Survey Bangladesh 2006. Dhaka, Bangladesh: Bangladesh Bureau of Statistics (BBS) and UNICEF, 2007.

http://www.unicef.org/bangladesh/200608 MICS 2006 keyb findings.pdf

10. Rowen T, Prata N, Passano P. Evaluation of a traditional birth attendant training programme in Bangladesh. Midwifery. 2011 Apr;27(2):229-36. http://dx.doi.org/10.1016/j.midw.2009.06 .003 Epub 2009 Jul 24. PubMed PMID: 19632016.

11. World Bank. Bangladesh health sector profile 2010. Washington D.C.: The Worldbank, 2010. http://documents.worldbank.org/curated/ en/2010/01/16270661/bangladeshhealth-sector-profile-2010

12. Pathmanathan I, Rahman S, Biswas $\mathrm{T}$, Nazneen QN, Khatun A, Mustafa M. Evaluation of Community-Based Skilled Birth Attendant Program in Bangladesh. Dhaka: Ministry of Health and Family Welfare, Bangladesh; UNFPA Bangladesh, 2010. 
13. BDHS. Bangladesh Demographic and Health Survey 2007. 2009. http://catalog.ihsn.org/index.php/catalog/ $\underline{142}$

14. Koblinsky MA. Community-Based Postpartum Care: An Urgent Unmet Need 2005. http://www2.pathfinder.org/site/DocServ er/Communitybased postpartum care.pdf

15. Islam $\mathrm{N}$, Islam $\mathrm{MT}$, Yoshimura $\mathrm{Y}$. Practices and determinants of delivery by skilled birth attendants in Bangladesh. Reprod Health. 2014 Dec 11:11:86. http://dx.doi.org/10.1186/1742-4755-1186 PubMed PMID: 25495451.

16. Islam MT, Islam N, Yoshimura $Y$, Nisha MK, Yasmin N. Newborn care practices in rural Bangladesh. Research and Reports in Neonatology. 2015;5:65-72. http://dx.doi.org/10.2147/RRN.S87122

17. MoHFW. Operational Guidelines on Community Support System. Dhaka, Bangladesh: Ministry of Health and Family Welfare, Government of the People's Republic of Bangladesh, 2008. http://www.google.com/url?sa=t\&rct=j\&q $=\&$ esrc $=$ s\&source $=$ web $\& c d=3 \& v e d=0 C$ CwQFjAC\&url=http\%3A\%2F\%2Ffamilyp lanning.care2share.wikispaces.net $\% 2 \mathrm{Ffi}$ le\%2Fview\%2FOperational\%2BGuidelin e\%2Bon\%2BCmSS.doc\&ei=tzRnVdnTG o hsATugoHYCg\&usg=AFQjCNF87HV X82GXeN9Sv49inPLXOUSpzA\&bvm=b v.93990622,d.cWc

18. MoHFW. National neonatal health strategy and guidelines for Bangladesh. Ministry of Health and Family Welfare (MoHFW), Government of the People's Republic of Bangladesh, 2009. https://extranet.who.int/nutrition/gina/site s/default/files/BGD\%202009\%20Nationa 1\%20Neonatal\%20Health\%20Strategy.p df
19. Wears RL. Advanced statistics: statistical methods for analyzing cluster and cluster-randomized data. Acad Emerg Med. 2002 Apr;9(4):330-41. http://dx.doi.org/10.1111/j.15532712.2002.tb01332.x PubMed PMID: 11927463.

20. Ukoumunne OC, Gulliford MC, Chinn S, Sterne JA, Burney PG. Methods for evaluating area-wide and organisationbased interventions in health and health care: a systematic review. Health Technol Assess. 1999;3(5):iii-92. http://dx.doi.org/10.3310/hta3050 PubMed PMID: 10982317.

21. Bang AT, Bang RA, Baitule SB, Reddy $\mathrm{MH}$, Deshmukh MD. Effect of homebased neonatal care and management of sepsis on neonatal mortality: field trial in rural India. Lancet. $1999 \mathrm{Dec}$ 4;354(9194):1955-61. http://dx.doi.org/10.1016/S01406736(99)03046-9 PubMed PMID: 10622298.

22. Bang AT, Bang RA, Reddy HM. Homebased neonatal care: summary and applications of the field trial in rural Gadchiroli, India (1993 to 2003). J Perinatol. 2005 Mar;25 Suppl 1:S10822.

http://dx.doi.org/10.1038/si.jp.7211278 PubMed PMID: 15791272.

23. Baqui $\mathrm{AH}$, Ahmed $\mathrm{S}$, El Arifeen $\mathrm{S}$, Darmstadt GL, Rosecrans AM, Mannan I, Rahman SM, Begum N, Mahmud AB, Seraji HR, Williams EK, Winch $P J$, Santosham M, Black RE; Projahnmo 1 Study Group. Effect of timing of first postnatal care home visit on neonatal mortality in Bangladesh: a observational cohort study. BMJ. 2009 Aug 14;339:b2826.

http://dx.doi.org/10.1136/bmj.b2826 PubMed PMID: 19684100. 
24. Baqui AH, El-Arifeen S, Darmstadt GL, Ahmed S, Williams EK, Seraji HR, Mannan I, Rahman SM, Shah R, Saha SK, Syed U, Winch PJ, Lefevre A, Santosham M, Black RE; Projahnmo Study Group. Effect of communitybased newborn-care intervention package implemented through two service-delivery strategies in Sylhet district, Bangladesh: a clusterrandomised controlled trial. Lancet. 2008 Jun 7;371(9628):1936-44. http://dx.doi.org/10.1016/S01406736(08)60835-1 PubMed PMID: 18539225.

25. Daga SR, Daga AS, Dighole RV, Patil RP. Anganwadi worker's participation in rural newborn care. Indian J Pediatr. 1993 Sep-Oct;60(5):627-30. http://dx.doi.org/10.1007/BF02821721 PubMed PMID: 8157331.

26. Daga SR, Daga AS, Dighole RV, Patil RP, Dhinde HL. Rural neonatal care: Dahanu experience. Indian Pediatr. 1992 Feb;29(2):189-93. PubMed PMID: 1592499.

27. Jokhio AH, Winter HR, Cheng KK. An intervention involving traditional birth attendants and perinatal and maternal mortality in Pakistan. N Engl J Med. 2005 May 19;352(20):2091-9. http://dx.doi.org/10.1056/NEJMsa04283 o PubMed PMID: 15901862.

28. Manandhar DS, Osrin D, Shrestha BP, Mesko N, Morrison J, Tumbahangphe KM, Tamang S, Thapa S, Shrestha D, Thapa B, Shrestha JR, Wade A, Borghi $\mathrm{J}$, Standing $\mathrm{H}$, Manandhar $\mathrm{M}$, Costello AM; Members of the MIRA Makwanpur trial team. Effect of a participatory intervention with women's groups on birth outcomes in Nepal: clusterrandomised controlled trial. Lancet. 2004 Sep 11-17;364(9438):970-9. http://dx.doi.org/10.1016/S01406736(04)17021-9 PubMed PMID: 15364188.
29. Addai I. Determinants of use of maternal-child health services in rural Ghana. J Biosoc Sci. 2000 Jan;32(1):115. PubMed PMID: 10676056.

30. Chakraborty N, Islam MA, Chowdhury $\mathrm{RI}$, Bari W, Akhter HH. Determinants of the use of maternal health services in rural Bangladesh. Health Promot Int. 2003 Dec;18(4):327-37. http://dx.doi.org/10.1093/heapro/dag414 PubMed PMID: 14695364.

31. Duong DV, Binns CW, Lee AH. Utilization of delivery services at the primary health care level in rural Vietnam. Soc Sci Med. 2004 Dec;59(12):2585-95.

http://dx.doi.org/10.1016/j.socscimed.20 04.04.007 PubMed PMID: 15474211.

32. Gage AJ. Barriers to the utilization of maternal health care in rural Mali. Soc Sci Med. 2007 Oct;65(8):1666-82. Epub 2007 Jul 23. http://dx.doi.org/10.1016/j.socscimed.20 07.06.001 PubMed PMID: 17643685.

33. Navaneetham K, Dharmalingam A. Utilization of maternal health care services in Southern India. Soc Sci Med. 2002 Nov;55(10):1849-69. http://dx.doi.org/10.1016/S02779536(01)00313-6 PubMed PMID: 12383469.

34. Onah HE, Ikeako LC, Iloabachie GC. Factors associated with the use of maternity services in Enugu, southeastern Nigeria. Soc Sci Med. $2006 \quad$ Oct;63(7):1870-78. http://dx.doi.org/10.1016/i.socscimed.20 06.04.019 PubMed PMID: 16766107.

35. Kaushal $M$, Aggarwal $R$, Singal $A$, Shukla H, Kapoor SK, Paul VK. Breastfeeding practices and healthseeking behavior for neonatal sickness in a rural community. J Trop Pediatr. 2005 Dec;51(6):366-76. Epub 2005 May 31.

http://dx.doi.org/10.1093/tropej/fmi035 PubMed PMID: 15927948 
36. Osubor KM, Fatusi AO, Chiwuzie JC. Maternal health-seeking behavior and associated factors in a rural Nigerian community. Matern Child Health J. 2006 Mar;10(2):159-69.

http://dx.doi.org/10.1007/s10995-0050037-z PubMed PMID: 16362233.

37. Ahmed S, Sobhan F, Islam A, Barkat-eKhuda. Neonatal morbidity and careseeking behaviour in rural Bangladesh. J Trop Pediatr. 2001 Apr;47(2):98-105. http://dx.doi.org/10.1093/tropej/47.2.98

PubMed PMID: 11336143.

38. Amin R, Shah NM, Becker S. Socioeconomic factors differentiating maternal and child health-seeking behavior in rural Bangladesh: A crosssectional analysis. Int J Equity Health. $2010 \quad$ Apr 3;9:9. http://dx.doi.org/10.1186/1475-9276-9-9 PubMed PMID: 20361875.

39. Koenig MA, Jamil $K$, Streatfield PK, Saha T, Al-Sabir A, El Arifeen S, Hill K, Haque $Y$. Maternal health and careseeking behavior in Bangladesh: findings from a national survey. Int Fam Plan Perspect. 2007 Jun;33(2):75-82. http://dx.doi.org/10.1363/3307507 PubMed PMID: 17588851.

40. Rahman M, Huq SS. Biodemographic and health seeking behaviour factors influencing neonatal and postneonatal mortality in Bangladesh: evidence from DHS data. East Afr J Public Health. 2009 Apr;6(1):77-84. http://dx.doi.org/10.4314/eajph.v6i1.457 54 PubMed PMID: 20000070.

41. Crissman HP, Engmann CE, Adanu RM, Nimako D, Crespo K, Moyer CA. Shifting norms: pregnant women's perspectives on skilled birth attendance and facility-based delivery in rural Ghana. Afr J Reprod Health. 2013 Mar;17(1):15-26. PubMed PMID: 24069731.
42. Choudhury N, Moran AC, Alam MA, Ahsan KZ, Rashid SF, Streatfield PK. Beliefs and practices during pregnancy and childbirth in urban slums of Dhaka, Bangladesh. BMC Public Health. 2012 Sep $17 ; 12: 791$. http://dx.doi.org/10.1186/1471-2458-12791 PubMed PMID: 22978705.

43. Metcalfe R, Adegoke AA. Strategies to increase facility-based skilled birth attendance in South Asia: a literature review. Int Health. 2013 Jun;5(2):96105.

http://dx.doi.org/10.1093/inthealth/ihs00 1 Epub 2012 Dec 19. PubMed PMID: 24030109.

44. Dey DK. Factors influencing maternal mortality in Bangladesh from a gender perspective. Sweden: Department of Family Medicine, Umea University, 1998.

http://www.popline.org/node/529786

45. NoorAli R, Luby S, Rahbar MH. Does use of a government service depend on distance from the health facility? Health Policy Plan. 1999 Jun;14(2):191-7. http://dx.doi.org/10.1093/heapol/14.2.19 1 PubMed PMID: 10538722.

46. Paul BK, Rumsey DJ. Utilization of health facilities and trained birth attendants for childbirth in rural Bangladesh: an empirical study. Soc Sci Med. 2002 Jun;54(12):1755-65. http://dx.doi.org/10.1016/S02779536(01)00148-4 PubMed PMID: 12113433.

47. Thaddeus S, Maine D. Too far to walk: maternal mortality in context. Soc Sci Med. $1994 \quad$ Apr;38(8):1091-110. http://dx.doi.org/10.1016/02779536(94)90226-7 PubMed PMID: 8042057. 
48. Puffer S, Torgerson D, Watson J. Evidence for risk of bias in cluster randomised trials: review of recent trials published in three general medical journals. BMJ. 2003 Oct 4;327(7418):785-9. doi: http://dx.doi.org/10.1136/bmj.327.7418.7 85 PubMed PMID: 14525877.

49. Darmstadt GL, Choi Y, Arifeen SE, Bari S, Rahman SM, Mannan I, Seraji HR, Winch PJ, Saha SK, Ahmed AS, Ahmed $\mathrm{S}$, Begum N, Lee AC, Black RE, Santosham M, Crook D, Baqui AH; Bangladesh Projahnmo-2 Mirzapur Study Group. Evaluation of a clusterrandomized controlled trial of a package of community-based maternal and newborn interventions in Mirzapur, Bangladesh. PLoS One. 2010 Mar 24;5(3):e9696.

http://dx.doi.org/10.1371/journal.pone.00 09696 PubMed PMID: 20352087

50. Islam MR, Odland JO. Determinants of antenatal and postnatal care visits among Indigenous people in Bangladesh: a study of the Mru community. Rural Remote Health. 2011;11(2):1672. Epub 2011 Jun 28. PubMed PMID: 21714582. http://www.rrh.org.au 